\title{
SOBRE A CORRELAÇÃO ENTRE A BIOÉTICA E A PSICOLOGIA MÉDICA
}

José Alvaro Marques Marcolino (in memorian), Claudio Cohen*

Trabalho realizado na Faculdade de Medicina da USP e na Faculdade de Ciências Médicas da Santa Casa de São Paulo, São Paulo, SP

\author{
*Correspondência \\ Rua Pedroso Alvarenga, \\ 1255 - conj. 21 \\ CEP 04531-012 \\ São Paulo - SP \\ ccohen@usp.br
}

\begin{abstract}
RESUMO
Os autores realizam um estudo a respeito de uma correlação entre a bioética e a psicologia médica. Dividem o trabalho em duas partes. A primeira discute os conceitos filosóficos sobre a distinção entre moral e ética, trata da ética ligada à medicina e dedica-se à bioética, procurando definir o que se compreende por essa disciplina, descrevendo seus três princípios básicos: a autonomia, a beneficência, não-maleficência e a justiça. Portanto, traça nesta parte do trabalho, uma trajetória que partiu da ética em sua vertente filosófica até chegar à ética em sua aplicação à medicina. A segunda parte é dedicada a definição do campo da psicologia médica, estudando aspectos da relação emocional do indivíduo doente com a sua doença, da relação do médico com a medicina e enfoca o relacionamento do médico com seu paciente. Discutem algumas situações clínicas em que se observa essa correlação. No final, buscam elaborar algumas conclusões.
\end{abstract}

Unitermos: Educação médica. Ética médica. Bioética. Psicologia médica. Relacionamento médico-paciente.

\section{INTRODUÇÃO}

"O remédio mais usado em medicina é o próprio médico, o qual, como os demais medicamentos, precisa ser conhecido em sua posologia, reaçôes colaterais e toxicidade" Michael Balint

O objetivo deste trabalho foi estudar os conceitos da bioética e da psicologia médica e discutir a hipótese de que exista uma correlação entre o campo de interesse destas duas disciplinas. A bioética é apresentada no contexto dado pelos princípios da autonomia, da beneficência e da justiça e a psicologia médica como um campo de estudo das relações humanas no terreno médico, ressaltando-se que é na prática clínica em que o médico se defronta com a sobreposição destas duas abordagens.

A primeira parte apresenta uma trajetória que parte da ética em sua vertente filosófica até chegar a ética aplicada à medicina. A segunda parte é dedicada ao campo da psicologia médica, em que foram estudados alguns aspectos da relação emocional do indivíduo doente com a sua doença, da relação do médico com a medicina e do relacionamento médico-paciente.

\section{Da ética a bioética}

Desde a mais remota antiguidade, o ser humano vem propondo diversas questões sobre o problema do bem e do mal, quais são os significados destes termos e se de seu conhecimento podem desprender-se normas de conduta que assegurem o bem pessoal e coletivo e nos eximam dos padecimentos que nos causamos e causamos aos demais por ignorá-los!.

A ética tem origem no grego ethikóse a moral no latim mores ${ }^{2}$, sendo ambos os termos referidos a costume, hábitos ou comportamento. Segundo Frankena ${ }^{3}$, a ética é um ramo da filosofia; é a filosofia moral ou pensamento filosófico acerca da moralidade, dos problemas morais e de juízos morais. Consiste em saber o que é correto ou incorreto, virtude ou vício, bondade ou maldade na conduta do homem ou entre um grupo de indivíduos. Jáa moralidade é é sob certo aspecto uma empresa social e não apenas uma descoberta ou invenção individual para orientação própria. Como a Língua, o Estado, a lgreja, ela precede o indivíduo, que a ela se acomoda e dela participa em maior ou menor escala e continua a existir mesmo depois de o indivíduo desaparecer.

O conceito de moralidade se apresenta como algo que guarda uma certa característica de exterioridade em relação ao indivíduo. Nos dizeres de Frankena $a^{3}$, "a moralidade não é social apenas no sentido de constituir num sistema que regula as relações de um indivíduo para com os outros; em verdade, tal sistema poderia ser uma construção inteiramente individual, como, quase inevitavelmente, são frutos de elaboração própria alguns itens do código pessoal de ação ante a outras pessoas. É social também, no que diz respeito a suas origens, sanções e função. É instrumento de que se vale a sociedade como um todo para orientação de grupos menores e de indivíduos. Faz aos indivíduos exigências que, inicialmente ao menos, são exteriores a eles".

A moralidade surge então, como objetivos culturalmente definidos e como um conjunto de regras a governar a consecução de tais objetivos, que permanecem mais ou menos exteriores ao indivíduo e que nele se impõe ou inculcam como hábitos. As regras da moralidade seriam incorporadas dentro de nós por meio de uma identificação com pessoas que tem significado em nossas vidas e que reforçam nossa noção do que é correto ou sanciona o que é incorreto.

Já o campo de interesse da ética surge para Frankena ${ }^{3}$ "quando ultrapassamos o estágio em que nos deixamos dirigir por normas tradicionais e ultrapassamos também o estágio em que essas regras se entranham em nós tão profundamente a ponto de dizermos que nos sentimos dirigidos do íntimo, ingressando no período em que 
Marcolino JAM et AL.

pensamos por nós mesmos em termos gerais e críticos e alcançamos uma espécie de autonomia na condição de agentes morais". Nessa concepção a ética adquire um caráter de interioridade em relação ao indivíduo e que transmite a noção de desenvolvimento.

Para Cohen \& Segre 4 , partindo de uma visão dinâmica, a moral é comparada com a função que a psicanálise atribui ao superego. $O$ superego 5 "é uma das instâncias da personalidade e tem uma função comparável à de um juiz ou censor em relação ao ego. O superego se forma através da introjeção das exigências e das proibições paternas. Freud fez questão de salientar que o superego é composto das percepções, das normas, das ordens e das leituras, ou seja, do mundo externo ao indivíduo". Ainda para Cohen \& Segre ${ }^{4}$, a moral pressupõe três características: I) seus valores não são questionados; 2) eles são impostos; 3) a desobediência às regras pressupõe um castigo.

Já a ética viria a ser algo a ser apreendido pelo indivíduo, vindo a se constituir como algo interno. Numa mesma comparação com a teoria psicanalítica, caberia ao ego cumprir a função ética, pois é esta instância psíquica que lida com as pulsões advindas do id, as ordens do superego e as exigências da realidade, funcionando como um mediador e unificador destas forças de interesses diferentes ${ }^{4}$.

O ego ${ }^{5}$ "encontra-se em relação de dependência tanto quanto às reivindicações do id como quanto aos imperativos do superego e às exigências da realidade, sendo que no indivíduo maduro ele deve funcionar como um mediador e unificador dessas forças de interesses diferentes". Cohen \& Segre 6 apontam que o indivíduo deva ser considerado ético quando possuir uma personalidade bem integrada, quer dizer, que tenha uma maturidade emocional que the permita lidar com emoções conflitantes, uma força de caráter, um equilíbrio de vida interior e um bom grau de adaptação à realidade do mundo. Consideram que a ética se vincula a três pré-requisitos: I) percepção (consciência) dos conflitos; 2) autonomia (condição de posicionar-se entre a emoção e a razão, sendo que essa escolha é ativa e autônoma); 3) coerência.

Nesse sentido, o desenvolvimento de uma atitude ética passa pela percepção de inúmeros conflitos, propostos pelo que diz o coração e o que a cabeça pensa. Ser ético é poder percorrer um caminho que é indicado pela emoção e pela razão, podendo posicionar-se na parte deste percurso que considerar mais adequada, na busca de uma atitude mais integrada, experimentada na prática da vida, em que se é capaz de levar em conta ambos os vértices, passando a poder ser responsabilizado e responsável pelos seus atos. A percepção do conflito psíquico, a liberdade e a coerência são as características fundamentais da ética. Esta concepção apresenta o posicionamento ético como um problema, pelo simples fato de que o indivíduo não nasce ético, e sim vai tornando-se ético com o seu desenvolvimento. Dito de outra maneira, o processo de humanização vai levando no seu interior à ética.

Para Freud, ${ }^{7}$ podemos rechaçar que exista uma capacidade original, ou natural, por assim dizer, de distinguir o bem do mal. Para Herrmann, ${ }^{8}$ "todos os catálogos éticos sempre contêm algum tipo de ordem contrária à natureza, senão nem valeria a pena escrevê-los. Ou são formulados por uma comissão de elite, que não sofre das premências do vulgo que os deve cumprir ou o são numa região diferente e com exigências diversas daquelas em que se pretende aplicá-los".

O que realmente parece acontecer é que não há intrinsecamente na natureza humana nada ético e que a ética é um epifenômeno surgido de uma variedade de atitudes conflitivas, nas quais o básico corresponde ao instinto, ao desprazer, aos impulsos agressivos, ao desejo de existir e outros fatores análogos'.

Tenembaum" aponta que "a ética está ligada à noção de conscientização". Isto decorre da visão psicanalítica da consciência e do processo de conscientização como funções ligadas ao desenvolvimento do ego, no qual o superego é um dos agentes impeditivos. Sendo a submissão uma exigência superegóica, a ética nada teria a ver com o superego. A ética não exige submissão; princípios éticos não são impostos, mas sim alcançados; as leis sim são impostas. A moral é imposta, a ética é percebidal0.

\section{A ética médica}

Segundo Moura Fé," "a necessidade ético-moral sinalizou parâmetros de comportamento em todas as esferas da atividade humana e, naturalmente, tinha de alcançar o exercício das profissões. Neste sentido, a medicina logo demonstrou preocupação com os ditames morais de sua prática, tendo um dos primeiros códigos de ética profissional conhecidos. Sendo uma profissão em constante contato com situações que envolvem a vida, a saúde, a doença e a morte, a atividade médica enseja, inevitavelmente, um campo propício às reflexões sobre o próprio sentido da existência. Ao mesmo tempo, por sua notável e necessária capacidade de inferência na vida das pessoas, traz a prática médica para o cotidiano das grandes questões da responsabilidade e dos limites de sua utilização".

A utilização dos conhecimentos médicos, que tantos benefícios trouxe e traz para a humanidade, tem de se fazer de acordo com certas regras conhecidas e estipuladas pela coletividade, de forma a assegurar o respeito à pessoa humana. A medicina, organizada dentro de um corpo teórico e prático, tem em nossos tempos motivos para orgulharse de seus surpreendentes avanços no conhecimento da estrutura e do funcionamento das partes que integram o organismo humano, de seus métodos para identificar as disfunções dos órgãos e determinar sua patologia e ainda mais, de seus recursos para prevenir e combater doenças. Tais avanços refletem, de certa maneira, a continua procura do ser humano em encontrar soluções que the assegurem um melhor bem-estar e resoluções para os problemas que lhe trazem incômodos.

É verdade que a medicina destas últimas décadas enriqueceu-se notavelmente e incorporou cada vez mais as descobertas e técnicas das ciências chamadas exatas e das ciências biológicas, sendo verdade também, que todo esse conhecimento deve ser assimilado pelo médico e aplicado ao homem doente.

Este mesmo notável progresso no campo das ciências biomédicas tem obrigado aos pesquisadores e o próprio médico a enfrentar novas situações que the exigem um questionamento a respeito de qual conduta correta e quem deve adotá-la. $\mathrm{O}$ empreendimento de tal desenvolvimento tem colocado quem o constrói, ou aquele que o aplica, dentro de uma determinada atitude ética. Cada passo e cada conquista da medicina é fruto de uma atitude ética, no sentido de que comporta uma discussão do que é bom ou mal para alguém, exigindo uma reflexão quanto às conseqüências desta mesma atitude, o que retorna em nova interrogação de fundamento ético. Poderíamos afirmar que todas as transformações por que tem passado o conhecimento médico trazem consigo novos conflitos éticos e obrigam a 
novas responsabilidades. A conduta médica não está determinada por um conjunto de regras absolutas que regem ações em circunstâncias especiais, senão constitui uma verdadeira e constante atitude no desenvolvimento da vida e no desempenho profissional.

Várias questões têm sido trazidas à discussão. $\bigcirc$ emprego de órgãos para transplante, o uso de bancos de órgãos e tecidos, as situações conflitivas nas quais intervêm os receptores, os doadores, os familiares e os membros da equipe médica; a inseminação artificial, com a conseqüente dificuldade de definir a legitimidade, o problema das relações familiares e os direitos de herança; a manipulação genética, no plano experimental da organização molecular da matéria viva; o desenvolvimento de novos produtos farmacológicos e os aspectos éticos da experimentação com seres humanos são exemplos de questões éticas surgidas com o desenvolvimento de novas tecnologias.

Numa sociedade considerada livre, em que os direitos humanos sejam reconhecidos e respeitados, o desenvolvimento destas novas possibilidades na área médica propiciou também a modificação da posição do paciente em relação ao que lhe é proposto pelo médico, em função do acesso à informação, da existência destes recursos postos a sua disposição, passando, então, a questionar a sua utilização, bem como exigir ser suficientemente esclarecido a respeito dos benefícios ou prejuízos obtidos com a sua utilização. Tähkä'2 afirma "o paciente de hoje não se vê mais no papel tradicional de se submeter sem queixas e sem perguntas a quaisquer medidas que o médico supostamente infalivel ache melhores. Ele espera que a sua individualidade seja respeitada e, graças aos veículos de comunicação, acha-se muito melhor informado sobre assuntos médicos do que as gerações anteriores".

Acompanhando este ponto de vista, o Código de Ética Médica ${ }^{13}$ inseriu normas deontológicas concernentes ao assunto no capítulo dedicado aos Direitos Humanos. Nele impede-se ao médico efetuar qualquer procedimento sem o devido esclarecimento e o consentimento prévios do paciente ou de seu representante legal.

O ser humano, até então, olhado como "coisa" pela ciência médica passa a exigir que a mesma medicina tenha que estruturar uma atitude que leve em consideração sua exigência de ser reconhecido como "sujeito". O ser humano enfermo, estudado em sua enfermidade de maneira "objetiva", torna-se num dado momento um sujeito, com quem o médico vai estabelecer uma relação humana e com quem passa a discutir as possibilidades que the são oferecidas.

Neste prisma, de reatualização das atitudes, também o médico deixa de ser "coisa". Poderíamos relembrar a discussão a respeito do consentimento informado, em que o médico deve prestar ao paciente todos os esclarecimentos necessários com relação a um determinado procedimento. Essa situação permite ao paciente interagir com as propostas do médico. Relembrar também, os permanentes conflitos pelos quais passam os médicos intensivistas, ao ter de optar por qual paciente terá sua vida mantida por aparelhos. Relembrar ainda, que desde que se possibilitou tecnicamente a realização de transplantes de órgãos, o profissional da saúde envolvido com esta prática nem por isso deixou de ter de lidar muitas vezes com o choque de valores dele profissional, do doador ou de sua família. Poderíamos, quem sabe neste ponto, sugerir o nome de "Ética do Sujeito" para exprimir tanto a dimensão humana do paciente quanto do médico.
A ciência médica, ao alcançar um incontestável progresso na oferta de soluções aos problemas de saúde dos indivíduos, vê necessária a elaboração de novas atitudes que orientem a aplicação destas mesmas soluções, e também, na medida de uma modificação na atitude social, na qual as pessoas são informadas e se tornam conscientes destas novas possibilidades, passam a exigir que o próprio médico os leve em consideração.

\section{Bioética}

A bioética veio a se constituir numa disciplina que procura integrar a cultura técnico-científica das ciências naturais com a cultura humanística. De acordo com Reich ${ }^{14}$, pode-se definir a bioética como "o estudo sistemático da conduta humana na área das ciências da vida e dos cuidados da saúde, na medida em que esta conduta é examinada à luz dos valores e princípios morais". Para Clotet, ${ }^{15}$ é a "expressão crítica do nosso interesse em usar convenientemente os poderes da medicina para conseguir um atendimento eficaz dos problemas referentes à vida, saúde e morte do ser humano".

Esta nova vertente da ética aplicada às ciências biomédicas apresenta um enfoque não só normativo, como é o caso dos códigos de ética, mas um enfoque de pesquisa a fim de que os aspectos normativos das éticas padronizadas possam ser reavaliados por meio de estudos multidisciplinares.

De acordo com Beauchamps e Chidress, ${ }^{16}$ os princípios da bioética são autonomia, beneficência, não-maleficência e justiça.

O princípio da autonomia, denominação mais comum pelo qual é conhecido o princípio do respeito às pessoas, exige que aceitemos que elas se autogovernem, sejam autônomas, quer na sua escolha, quer nos seus atos. O princípio da autonomia requer que o médico respeite a vontade do paciente ou do seu representante, em seus valores morais e crenças. Reconhece o domínio do paciente sobre a própria vida e o respeito à sua intimidade. Limita, portanto, a intromissão dos outros indivíduos no mundo da pessoa que esteja em tratamento.

O princípio da beneficência requer que sejam atendidos os interesses importantes e legítimos dos indivíduos e que, na medida do possível, sejam evitados danos. Esse princípio se ocupa da procura do bem-estar e interesses do paciente por intermédio da ciência médica e de seus representantes ou agentes.

Já o princípio da não-maleficência está fundamentado na imagem do médico que perdurou ao longo da história e que está fundada na tradição hipocrática: "usarei o tratamento para o bem dos enfermos, segundo minha capacidade de juízo, mas nunca para fazer o mal e a injustiça; no que diz respeito às doenças, criar o hábito de duas coisas: socorrer, ou, ao menos, não causar danos".

princípio da justiça exige eqüidade na distribuição de bens e benefícios no que se refere ao exercício da medicina ou área de saúde. Uma pessoa é vítima de uma injustiça quando the é negado um bem ao qual tem direito e que the é devido. Assim como o princípio da autonomia é atribuído, de modo geral, ao paciente, e o da beneficência ao médico, o da justiça pode ser postulado, além das pessoas diretamente vinculadas à prática médica (médico, enfermeira e paciente), por terceiros, como poderiam ser as sociedades para a defesa dos direitos da criança, em defesa da vida, ou grupos de apoio à prevenção da AIDS, cujas atividades e reclamações exercem uma influência notável na opinião pública através dos meios de comunicação social. 


\section{Da psicologia médica}

que é psicologia médica? Em que pese tão difundida, essa afirmação esconde uma pluralidade de concepções.

Em 1922, Ernst Kretschmer", dito o "patriarca da psicologia médica" ${ }^{18}$, aplica essa denominação a uma disciplina especial. Para Kretschmer ${ }^{17}$, o médico de espírito aberto sente no seu aprendizado uma dupla lacuna. Ele necessita de uma psicologia surgida da prática médica e que se destina aos problemas práticos de sua profissão. Isto é principal. Além disto, a busca da psicologia corresponde freqüentemente ao desejo do médico de penetrar além das quatro paredes da sua competência, na região espiritual da psicologia do reconhecimento nos problemas éticos e estéticos da vida dos povos, ligando organicamente seu círculo de pensamentos médicos e de ciências naturais ao horizonte da ciência espiritual.

Para Shneider ${ }^{19}$, a meta primordial da psicologia médica consiste em "preparar psicologicamente o médico com o objetivo de que possa melhor compreender o paciente". A aprendizagem da psicologia médica não é exclusivamente aquisição de conhecimento, senão em boa parte preparação humana para o exercício da medicina, implicando também a personalidade do aluno. Se o aluno acaba o curso de psicologia sem haver mudado em nada suas atitudes, se impõe uma revisão do procedimento.

Delay \& Pichot ${ }^{20}$ conceituam a psicologia médica como nada mais que uma atitude ante a doença e o doente, simples atitude interna que cumpre ao médico aprender a cultivar, qualquer que seja o ramo da clínica a que tenha a intenção de se dedicar, para o que se fará mister, então, ampliar e aprofundar, quanto possível, sua capacidade de compreensão, não apenas para a sondagem de correlações admissíveis entre enfermidade-enfermo, mas para conhecer melhor os diversos tipos de pacientes que venham a confiar em seus cuidados, e diante dos quais há que saber modular sua conduta para maior adequação e eficácia de sua assistência e tratamento.

Por psicologia médica, Jeammet et al. ${ }^{21}$ entendem "a disciplina ou ramo de estudo médico que visa proporcionar ao médico e profissionais de saúde informações e conhecimentos suficientes para que ele possa compreender o doente enquanto pessoa humana portadora de uma doença, facilitando a aplicação dos conhecimentos médico-científicos. Visa também a formação do próprio profissional de saúde por meio do conhecimento do desenvolvimento psicológico de seu "status" e "papel" profissional, consideradas as implicações pessoais e sociais de sua atuaçãa. Mais ainda, os estudos e o desenvolvimento de técnicas e atitudes dirigidas para o momento em que dois seres se encontram, estabelecendo a relação médico-paciente. Portanto o campo de estudo da psicologia médica envolve a compreensão psicológica do doente enquanto ser humano, as implicações psicológicas do papel do médico e o relacionamento médico e paciente".

Para Perestrello22, a psicologia médica é a psicologia da relação médico-paciente; é a psicologia da prática clínica, tendo como principal objetivo de estudo, as relações humanas no contexto médico; compreensão do homem em sua totalidade, diálogo permanente entre a mente e o corpo, na sua condição biopsicossocial, ou seja, a medicina da pessoa.

Para Mello Filho, ${ }^{23}$ a psicologia médica abrange o ensino ou a prática de todo tipo de fenômenos de saúde e de interações entre pessoas, como as relações profissionais-pacientes, as relações humanas dentro de uma família ou de uma instituição de saúde, a questão das doenças agudas ou crônicas, o papel das reações adaptativas ao adoecer, a invalidez, a morte, os recursos terapêuticos extraordinários.

A entrada da psicologia no currículo médico se deve, em primeiro lugar, ao reconhecimento cada vez mais generalizado do excesso de enfoque ao estudo das ciências voltadas às vertentes somatobiológicas do ser humano, o que acabou mutilando a imagem geral do homem.

Ao lado dessa questão, foi a mudança e reformulação do conceito de saúde e doença pela Organização Mundial de Saúde. A noção anterior definia saúde simplesmente como ausência de doença. Hígido ou sadio era o indivíduo cujo organismo se encontrava íntegro do ponto de vista da anatomia, fisiologia e histologia. O novo conceito de saúde pela Organização Mundial de Saúde, definida agora como um "estado de completo bem-estar físico, mental e social", tornou-se claro o quanto era necessário modificar o currículo médico clássico. O currículo antigo embora oferecesse correto entrosamento lógico-formal das disciplinas, na verdade desumanizava o exercício da clínica. Havia um peso maior a tecnologização do homem, deixando de lado um cunho mais humanista. $O$ novo currículo trouxe à tona esta nova exigência e o quanto se necessitava levar em conta a individualidade ${ }^{24}$. Para Najul, ${ }^{25}$ definir saúde para todos é uma proposta na ordem de um processo de construção da potencialidade total do sujeito social, uma potencialidade que parte da consideração do homem como ser ontológico, como totalidade biológico-social, submetido à dupla dimensão das leis biológicas e sociohistóricas.

Então, como disciplina específica, a psicologia médica foi introduzida nas escolas médicas na década de 60. No entanto, o processo de modificação das atitudes é lento, pois 20 anos depois seu lugar no currículo de diversas instituições, suas fontes referenciais e objetivos educacionais mostravam-se mal definidos em vários países europeus ${ }^{26}$.

Em nosso meio a situação também não é diferente, pois em 1969 , - Conselho Federal de Educação determinou que nos cursos de medicina se ministrasse o estudo dos fundamentos psicológicos da relação médico-paciente, não sendo ainda a psicologia médica uma disciplina específica ${ }^{27}$. Em pesquisa realizada por Giglio ${ }^{28}$, com relação à situação do ensino da psicologia médica, mostrava que, em | 981, das 4 I instituições que responderam a uma enquete, somente em 73\% a disciplina constava do currículo.

Cabia então à psicologia médica o papel de oferecer ao estudante de medicina uma perspectiva de visão mais global do homem. Cabia a psicologia ser o elo entre as ciências naturais e as ciências humanas. Equivale então dizer que, a psicologia médica é uma espécie de propedêutica antropológica, fornecendo ao estudante de medicina um complemento cultural humanístico, estudo compreensivo do homem, dentro de uma faixa de normalidade.

A noção de que a doença não é simples evento biológico acidental, decorrente de lesão anatômica de um sistema ou aparelho e que se constitui em situação complexa que envolve a totalidade da pessoa humana, sendo que nem todos vivem a doença do mesmo modo.

Na visão de Muniz \& $C_{h a z a n}{ }^{29}$ o ensino da psicologia médica se dá na prática, pois as vivências do aprendizado médico no hospital-escola, na relação com os professores, no acompanhamento das várias etapas de formação médica do primeiro ao sexto ano, do contato com o cadáver à pessoa doente. Também se da na prática médica, no ambulatório, 
enfermaria, unidade de emergência, na UTI, hemodiálise, transplantes e suas conseqüências para a pessoa doente; no contexto familiar; o doente agudo; crônico e o terminal; a relação médico-paciente nas várias especialidades; a equipe de saúde; nas relações interpessoais entre médicos e os profissionais de saúde; o médico enfermo, etc.

\section{Discussão}

A clássica frase do médico inglês Michael Balint ${ }^{30}$, citada na epígrafe deste trabalho, compara o médico com os demais medicamentos usados em medicina, apontando para a importância de sua utilização na prática médica, ressaltando a necessidade de se compreender o seu emprego e também os seus efeitos colaterais.

A observação mais atenta da expressão - o remédio mais usado em medicina - traz consigo uma dupla conotação. O significado de "usado", pode ser entendido como sinônimo de "usual, habituado, acostumado, afeiçoado ou deteriorado pelo uso: gasto"2.

Deste modo, "usado" poderia ser entendido de duas maneiras. Em primeiro lugar, como a expressão da ação e interferência da pessoa do médico na vida de seu paciente, de onde se deva conhecer suas indicações e efeitos colaterais. Um segundo sentido apontaria para o uso da pessoa do médico na relação com seu paciente, só que desta feita o médico sofreria e seria atingido por esta relação.

Estas duas maneiras de abranger a utilização da "substânciamédico" revelam a nosso ver, a participação do médico e do paciente como agentes ativos e passivos de um mesmo processo. Pensamos que este modo de compreender a utilização do médico conduz a uma concepção mais humanizada e mais real da relação médico-paciente, pois assenta tanto o médico quanto o paciente numa posição de sujeitos que interferem, ao mesmo tempo, um na vida do outro.

Dentro desta visão de interferência recíproca do médico e do paciente, partimos, então, para estudar a correlação entre as disciplinas da bioética e da psicologia médica.

De acordo com Clotet $^{15}$, a bioética pode ser entendida como a expressão crítica do nosso interesse em usar convenientemente os poderes da medicina para conseguir um atendimento eficaz dos problemas referentes à vida, saúde e morte do ser humano ao discutir o campo de aplicação e de verificação dos princípios da autonomia do paciente, da beneficência dos atos da medicina e o da justiça da relação entre estes agentes. Portanto, estaria incluído o estudo das ações e reações, tanto do médico quanto do paciente.

Paralelamente, a relação do médico-paciente é parte do campo de estudo da psicologia médica. Nos dizeres de Muniz e Chazan"29, "a psicologia médica constitui-se numa disciplina que pretende estudar a psicologia do estudante, do médico, do paciente, da relação entre estes, da família e do contexto institucional destas relações".

Ambas as disciplinas se correlacionam ao discutir a utilização da substância médico.

Alguns autores nos têm chamado a atenção para a possibilidade de sobreposição destas duas perspectivas, ou seja, da discussão de temas ligados a bioética e à psicologia médica. Martins et al. ${ }^{31}$ afirmam que "os dilemas éticos em medicina se dramatizam na relação médico-paciente" e nos apresentam alguns exemplos típicos de situações hospitalares emque se podem observar este contexto: I) $O$ paciente oferece resistência a uma intervenção cirúrgica, mutiladora, necessária e impostergável; 2) O paciente por razões religiosas, não aceita a transfusão de sangue; 3) A família do paciente que quer retirá-lo do hospital e ameaça a equipe médica, acusando-a de negligência ou omissão; 4) 0 paciente aidético, gravemente enfermo, que de maneira ambivalente, pede alta hospitalar; 5) O pedido de avaliação psiquiátrica para indicar ou não uma intervenção cirúrgica ou um transplante de órgão; 6) O pedido de avaliação psicológica para indicar ou não uma cirurgia de alteração do sexo; 7) O médico que se recusa a prestar assistência a pacientes aidéticos ou a um paciente que o agrediu verbalmente; 9) O médico que pede ajuda ante a situações em que tem de fazer comunicações dolorosas aos pacientes, como paciente com AIDS. Como contar, a quem contar e, principalmente, o quê contar?

Esses exemplos trazem a interrogação sobre questões como as que envolvem os critérios para definir a necessidade de uma intervenção cirúrgica, dilema a respeito da qualidade de vida de um paciente com doença crônica, das questões morais e religiosas que se sobrepõem aos determinantes científicos, sobre o envolvimento emocional entre médico e seu paciente, sobre o papel do emocional nas decisões de um paciente, ou ainda, sobre o médico que se vê obrigado a lidar com suas limitações.

Todas essas questões discutem quais são os limites da autonomia do paciente, quais critérios definem a beneficência dos atos médicos e mais ainda, sobre o que se pode considerar como justo no que se refere à distribuição dos cuidados à saúde, pontos estes que buscam tradução por meio do campo da bioética.

Evidenciam também o surgimento de um campo dinâmico psicológico, que se desenvolve na interação entre o médico e seu paciente, a família do paciente e a equipe médica, entre todos os membros da equipe de saúde e a instituição de assistência e, do próprio médico para com ele mesmo, debatendo o papel da utilização do trabalho médico, campo este que é objeto de estudo da psicologia médica.

Reforçando esta correlação, Lo \& Schroeder ${ }^{32}$ investigaram a freqüência de dilemas éticos em uma enfermaria de um hospital geral. Os principais problemas éticos identificados neste estudo foram: I) Decidir sobre a manutenção ou descontinuidade de tratamento em casos graves; 2) Lidar com situações nas quais o paciente não aceita continuar um tratamento e/ou se submeter a um procedimento; 3) A comunicação da verdade; 4) Questões envolvendo conflitos entre condutas médicas; 5) Situações nas quais por razões sociais um paciente é internado com muita freqüência.

Em nosso meio, um estudo conduzido por Taquette et al. ${ }^{33}, 62,7 \%$ de estudantes de medicina de $5^{\circ}$ e $6^{\circ}$ ano sugerem temas a serem desenvolvidos durante o curso médico referem-se a prática médica Os temas sugeridos com mais freqüência foram comunicar diagnósticos de doenças graves; relação médico-paciente; eutanásia; aborto; sigilo médico; erro e negligência médica, iatrogenias, omissão de socorro; doação de órgãos; e ética e sexualidade. Nem sempre ficam no campo da ética, mas se referem também a dificuldades enfrentadas na prática clínica e que não são suficientemente consideradas ao longo do curso. Por outro lado, pediam a estrita correlação entre os temas tratados em sala de aula e o que eles estavam vivenciando em suas práticas: "Acho que se deve estabelecer ligação entre os grandes temas de bioética e a experiência prática dos alunos". 
Marcolino JAM et AL.

Pode ser observado então, que embora estes autores em seu estudo estivessem focalizando a freqüência de problemas éticos em enfermarias de um hospital geral, as situações encontradas guardam as mesmas questões que poderiam ser discutidas pela psicologia médica.

\section{ConCLUSÃo}

Podemos concluir que o desenvolvimento de uma atitude ética passa pela percepção dos inúmeros conflitos propostos pelo emocional e pelo racional, vinculados ao entendimento das experiências que vão se acumulando e que resultam, posteriormente, na compreensão de um sentido. A percepção do conflito psíquico, a liberdade e a coerência são as características fundamentais da ética.

O respeito à autonomia do paciente confronta o médico com seus próprios valores e com os do paciente. É no contato diário com o seu paciente que o médico interroga qual conduta possa ser considerada correta ou incorreta numa ou noutra situação.

No que se refere à discussão dos princípios da bioética aplicados à prática clínica é fundamental que se inclua a dimensão emocional que surge da relação do médico com o paciente, com a instituição e com o que se considera justo nos modelos de assistência à saúde.

A discussão dos aspectos emocionais que envolvem a relação do médico com seu paciente não prescinde da dimensão ética na prática clínica.

Os profissionais de saúde precisam estar familiarizados com a bioética. A bioética clínica procura integrar os conceitos e teorias éticas às responsabilidades clínicas. A bioética clínica é por sua vez uma prática interpessoal e intrapessoal envolvendo aspectos do relacionamento do médico com seu paciente.

Deve-se estimular a criação de disciplinas ministradas na graduação médica, que levem em conta a bioética clínica e a psicologia médica, propiciando a preparação conveniente dos respectivos professores e alunos e que auxilie na preparação humanista dos futuros médicos.

\section{Conflito de interesse: não há}

\section{SUMMARY}

\section{About correlation between bioethics and medical PSYCHOLOGY}

The authors make astudy about the correlation between bioethics and medical psychology. They divide the study in two parts. The first part they discuss the philosophical concepts about the distinction between morals and ethics, they deal with ethics applied to medicine and they are trying to define what is meant by subject and describe its three basic principles: autonomy, beneficence, non maleficence and justice. Consequently in this part they trace route that started from ethics in its philosophical origins and moved on to ethics in its application to medicine. The second part is dedicated to the definition of the field of study of medical psychology, they study some aspects of the emotional relation of the patient with his illness, the relation of the doctors of his medicine and the relacionship between doctor and his patient. They discusse some clinical issues where they observe this correlation. At last, they try to draw some conclusions. [Rev Assoc Med Bras 2008; 54(4): 363-8]

KEY wORDS: Medical education. Medical ethics. Bioethics. Medical psychology. Doctor-patient relationship.

\section{REFERÊNCIAS}

I. Klimovsky G, Dupetit S, Zysman S. El origen de los conceptos éticos en Freud. In: XVIII Congresso Latino Americano de Psicanálise Fepal, Rio de Janeiro, 1990. p.20-5.

2. Ferreira $\mathrm{ABH}$. Novo dicionário da língua portuguesa. Rio de Janeiro: Nova Fronteira; 1986.

3. Frankena WR. Ética. Rio de Janeiro: Zahar; 1981.

4. Cohen C, Segre M. Breve discurso sobre valores, moral, eticidade e ética. Bioética, v.2, n. I, p. 19-24, 1994.

5. Laplanche J, Pontalis JB. Vocabulário de psicanálise. Rio de Janeiro: Martins Fontes; 1970.

6. Cohen C, Segre M. Definição de valores, moral, eticidade e ética. In: Segre M, Cohen C, organizadores. Bioética. São Paulo: EDUSP; 1995. p. I3-22.

7. Freud S. O mal estar da civilização. Rio de Janeiro: Imago; 1976. v.2I, Edição Standart Brasileira das Obras Completas .

8. Herrmann F. Psicanalética. Rev Ide-SBPS. 1995;27: I0-9.

9. Tenenbaum D. Crônica de um hospital geral: $\vee$ criando monstros. Rev. Ide-SBPSP. | 995;26:88-9|.

10. Cohen C, Marcolino JAM. Aspectos éticos. In: Cordás TA, Moreno RA, editores. Condutas em psiquiatria. São Paulo: Lemos Editorial; 1995. p.37-46.

I I. Moura Fé IA. Prefácio. In: Desafios éticos. Brasília (DF): CFM; I 993. p.9- I I .

12. Tähkä V. O relacionamento médico-paciente. Porto Alegre: Artes Médicas; 1988.

13. Código De Ética Médica. Brasília (DF): Conselho Federal de Medicina; 1988.

14. ReichWT, editor. Encyclopedia of bioethics. New York(NY): FreePress; 1978.

15. Clotet J. Por que bioética? Bioética. 1993; I:13-9.

16. Beauchamp TL, Childress JF. Principles of biomedical ethics $3^{\text {rd }}$ ed. New York (NY): Oxford University Press; 1989.

17. Kretschmer E. Psicologia médica. I3 ed. Rio de Janeiro: Atheneu; 1974.

18. Melo ALN. Psiquiatria. Rio de Janeiro: Guanabara Koogan; 1981.

19. Schneider PB. Psicologia aplicada a la practica médica. Buenos Aires: Editorial Paidos; 1974.

20. Delay J, Pichot P. Psicologia. Rio de Janeiro: Masson; 1982.

21. Jeammet P, Reynaud M, Consoli S. Manual de psicologia médica. São Paulo: Durban; 1989.

22. Perestrello D. A Medicina da pessoa. Rio de Janeiro: Atheneu; 1974.

23. Mello Filho J. Psicossomática hoje. Porto Alegre: Artes Médicas; 1992.

24. Pontes JF. O ensino da psicologia no currículo médico. In: Reunião da Associação Brasileira de Escolas Médicas, Salvador; 1966. ABEM; 1966. Anais.

25. Najul LM. La educacion medica y la salud para todos. Educ Med Salud. 1991;25:432-8.

26. Sutter JM, Scotto JC. Place de la psychiatrie et de la psychologie dans les études médicales modernes. Confront Psychiatr. 1979; 17:193-216.

27. Botega NJ. O ensino da psicologia médica no Brasil: uma enquete postal. Rev ABP-APAL. 1994; | 6:45-51.

28. Giglio JS. A situação do ensino de psicologia médica no Brasil hoje. In: Knobel M, Saidemberg S. Psiquiatria e higiene mental. São Paulo: Editora Autores Associados; 1983.

29. Muniz JR, Chazan LF. Ensino de psicologia médica. In: Mello Filho J, editor. Psicossomática hoje. Porto Alegre: Artes Médicas; 1992. p.37-44.

30. Balint M. O médico, seu paciente e a doença. Rio de Janeiro: Atheneu; 1984.

31. Martins LAN, Marco MA, Manente MLF, Noto JRS, Bianco MB. Dilemas éticos no hospital geral. Bol Psiquiatr. 1991;24:28-34.

32. Lo B, Schroeder SA. Frequency of ethical dilemmas in a medical inpatient service. Arch Intern Med. 1981; | 41: I 062-4.

33. Taquette SR, Rego S, Schramm FR, Soares LL, Carvalho SV. Situações eticamente conflituosas vivenciadas por estudantes de medicina. Rev Assoc Med Bras. 2005;51:23-8.

Artigo recebido: 24/1 I/07

Aceito para publicação: 01/03/08 